\section{The learning organization ten years on: a case study}

Peter A.C. Smith
The author

Peter A.C. Smith is President, The Leadership Alliance Inc., Toronto, Canada and Professor of Management, Action Learning, Canadian School of Management.

\section{Keywords}

Organizational learning, Continuing development

\section{Abstract}

Asserts that in dealing with change the mindsets of an enterprise's managers are key to its viability. States that by developing a learning organization an enterprise attempts to avoid the mindset problem by fostering a climate of learning; however, claims that over the last decade such development has not in general been successful and contends that this has been largely because of impractical implementation approaches. Based on the author's practice, maintains that the learning organization is indeed a useful metaphor for successfully dealing with change. Describes the author's implementation approach which is based on two simple notions: first, that the best way to deal with mindsets is to keep them from hardening; second, that by changing activities and tools one can change habits of thinking and learning. Illustrates the approach by detailing a long-term case study involving a large and very successful financial services enterprise which has successfully adopted learning organization principles.

\section{Electronic access}

The current issue and full text archive of this journal is available at

http://www.emerald-library.com

The Learning Organization

Volume $6 \cdot$ Number $5 \cdot 1999 \cdot$ pp. 217-223

(C) MCB University Press · ISSN 0969-6474

\section{Introduction}

Change is a topic of crucial concern to all organizations in these turbulent business times. In dealing with change, and ultimately in ensuring business survival of an organization, I concur with authors such as Senge (1990) that managements' mindsets are the most critical factor. How and why managers' minds tend to become set in certain patterns, and how this results in catastrophic corporate and personal upheaval as a sporadic but inevitable feature of today's typical organizations, has been detailed elsewhere (Smith and Saint-Onge, 1996).

Many authorities believe the answer to the mindset problem lies in continuously upgrading and leveraging the knowledge base of the organization. This is done by fostering a climate of learning for employees, and particularly for managers. A company adhering to this philosophy has come to be called a learning organization (LO). Over the last ten years the LO has been widely promoted as having the necessary attributes to address successfully critical change-related business issues (Senge, 1990).

Unfortunately, in spite of more than a decade of practice, developing an LO as traditionally undertaken has proven both difficult and career-hazardous, with few demonstrably successful examples (Smith and Tosey, 1999). Garvin's remark in 1993 seems in general to ring as true as ever "... despite the encouraging signs, the topic [Building a Learning Organization] in large part remains murky, confused, and difficult to penetrate" (Garvin, 1993).

On the other hand, although based more narrowly, my own practice has confirmed that the LO is indeed a useful organizational metaphor for successfully dealing with change. I contend that the general lack of LO progress over the last ten years has in large part been due to impractical implementation methods based on wishful thinking, and an overemphasis on "learning techniques". Psychosocial (Argyris, 1993) and cultural (Schein, 1992; Hampden-Turner, 1992) methodologies have also in my opinion been introduced at too early a stage in most cases.

Part of the problem is that the LO concept is like a cubist painting - full of ambiguous viewpoints. For example in Garvin's opinion “... [their] discussion of Learning Organizations have often been reverential and utopian, filled with near mystical terminology. Paradise they would have you believe, is just around the corner" (Garvin, 1993). Handy 
says: "The Learning Organization is a term commonly in vogue. It is however, less than obvious what it means, except that clearly it is a good thing to strive to be" (Handy, 1990); Senge, the LO's principal popularizer says: "There is no such thing as a Learning Organization. Learning organization is a category that I create in language....we are taking a stand for a vision ... it is not the vision but what it does that matters ..." (Kofman and Senge, 1993). For my part, I have followed Pedler et al. (1989) in viewing the LO as a metaphor which must be interpreted by each organization/practitioner to suit their own context; an example is given in Drew and Smith (1995).

Furthermore, as Garvin puts it, "Beyond high philosophy and grand themes lie the gritty details of practice" (Garvin, 1993). Anyone who has had practical experience of embarking on a LO initiative knows how difficult the planning task quickly becomes, and how rapidly organizational resistance forms. These practical difficulties result from not only the systemic complexity of the LO concept and the mindsets discussed previously, but also because not everyone is a self-motivated natural learner. For example, in my experience, managerial communities seem to break down into 15 per cent of individuals who are active continuous learners, 60 per cent of individuals who have potential for some form of learning if they can be convinced of its necessity, and 25 per cent "couch-potatoes" who are blocked from learning for various reasons. This is not to say that psychological (Argyris and Schon, 1978), social (Schein, 1992), and metanoic (Senge, 1990) approaches are not effective in the long term. However, they are very difficult to introduce unless a supportive environment already exists, and the initiating-practitioners are dedicated and courageous. Given even the most advantageous conditions, an initial successful intervention may still convince the organization's members to band together to get rid of the intruding culture. Practitioners will invariably conclude that these routes are not sufficiently robust and practical in the formative stages to carry the weight of the LO or its look-alikes to the "point of no return".

How then can the LO be developed? My approach, illustrated here via a case study, has been based on two simple notions originally applied in the 1980s (Smith, 1993): first, that it is critical to renew management mindsets and keep them from hardening; secondly, that by changing activities and tools one can change habits of thinking and learning. These principles are applied regardless of organizational size.

To this end, various systemic initiatives are designed and introduced. These initiatives are capable of incremental implementation and are founded on familiar practical behavioural enablers. Other organizational development methods (Senge, 1990; Argyris, 1993; Schein, 1992; Hampden-Turner, 1992) can be introduced and will take hold when this supportive environment has matured.

An overview of this very practical approach to LO development, and an illustrative case study, are presented in the following sections.

\section{Foundations for successful learning organization development}

I have always believed the LO flourishes best in the region of disequilibrium between an organization's formative and normative operational activities (Smith and Saint-Onge, 1996). LOs bring the formative-normative exploration-exploitation tension into a special kind of balance, so that new ideas and innovative genotypes are forever nibbling away at the status quo, and minds have no opportunity to become set. However, if the LO slips too far into the high-risk formative mode or the die-hard normative mode it loses these desirable properties. Disequilibrium is fostered by deliberately structuring the LO to promote creativity, learning and responsiveness to its environment; these depend on having fluid mindsets. My intent therefore has always been to design and develop a LO in a specific, very practical fashion such that there is a very rapid and continuous exchange between explicit and tacit adaptive/generative knowledge, with the result that mindsets have little opportunity to become frozen. The key to maintaining this balance is the judicious exercise of leadership and strategy.

In the traditional approach to LO development, practitioners attempt to encourage development of the self-renewing, reflective practices critical for business success (Morris, 1995), by explicitly focusing on learning. Learning techniques are introduced rather than business techniques as the first step. As noted previously, learning does not come easily to everyone. My approach to LO development accomplishes the same goals by reversing this 
process. In this regard I take Drucker (1992) quite literally when he asserts that "There is a need to change deeply ingrained habits to deal with the turbulent change upon us. What these needs require are changes in behaviour. But 'changing culture' is not going to produce them". and "If you have to change habits, don't change culture, change habits. And I know how to do that" (my italics).

I deliberately design the systemic structure, processes and tools to specifically develop an environment where learning will be essential to carrying out the roles of all employees. By changing the roles, all employees including managers are forced to change their habits of thinking and learning without necessarily being made aware that this is happening. That is, learning is made an implict element of the business processes. In this way 75 per cent of the community will be learning rather than just the 15 per cent natural learners. Indeed, since the emphasis is placed on performance, driven by business outcomes, the whole organization is concentrating its energies towards its own continuing business viability.

As we know, culture evolves as individual workers perform everyday activities. In the case study described here, and in other work that I have carried out, the LO culture is "pulled" into being by mandating the new structure, processes and tools. The traditional LO approach is based on first changing the organization's culture; however, trying to change the way an organization goes about its work by first changing its culture is like pushing on a rope.

In the LO, the essence of innovation is to recreate the world according to a particular ideal or vision. The knowledge involved has to be built, and requires frequent and laborious interaction among members of the organization. The disorder and interaction in the LO give rise to true learning. Nonaka and Takeuchi (1995) assert that "The major job of managers is to direct this confusion toward purposeful knowledge creation. Both senior and middle managers do this by providing employees with a conceptual framework that helps them make sense of their own experience”. Drucker (1993) has suggested “... one of the most important challenges for any organization is to build systematic practices for managing a self-transformation"; in the LO this second-order learning (Ackoff, 1981) must be an everyday task. The LO develops "dynamic capabilities" which are the organizational abilities to learn, adapt, change, and renew over time, based on search, problem solving and problem finding at the organizational level. These dynamic capabilities are exercised in the tension which exists between the need to operate from sound business foundations and the need for fundamental business transformation over time.

The above aims are achieved using two conceptually simple and intuitively attractive concepts in combination. The first is a workplace-based learning strategy; the second is a performance framework.

Figure 1 illustrates how a simple learning cycle, such as that which forms the heart of Deming's quality cycle, can be revised to give employees a sense of how to carry out their jobs in better fashion. In this strategy, one first carries out a prescribed role, then one reviews the results and reaches some conclusion with regard to the results achieved, then, as necessary, one plans to develop or use one or more "enablers" to try to improve the way in which one carries out the role next time, or indeed to revise the role itself. Enablers are simply anything which will help to improve performance; for example, an enabler could be some particular understanding, knowledge, activity, capability or attribute. It could be something as difficult as learning a new skill, or as simple as talking to an associate more often. The learning strategy is embedded in the organization through simple workshops, e.g. role of the manager workshops. During these sessions participants are also exposed to the power of collaborative learning, as shown in Figure 2. In principle all of this can be classed as a kind of action learning (Pedler, 1991) although it would not be presented to participants in these terms.

Figure 3 illustrates the performance framework in which the learning strategy is implemented. Performance is driven by the business outcomes desired, and thus promotes individual and cluster autonomy while maintaining alignment. The three performance elements are:

(1) Focus (clear definition of the performance desired).

(2) Will (attitudes and emotions consistent with focus).

(3) Resources (wherewithal to carry out focus).

These three performance factors are represented in Figure 3 by three circles in a Venn diagram. The more harmonious the factors 
Figure 1 The learning cycle

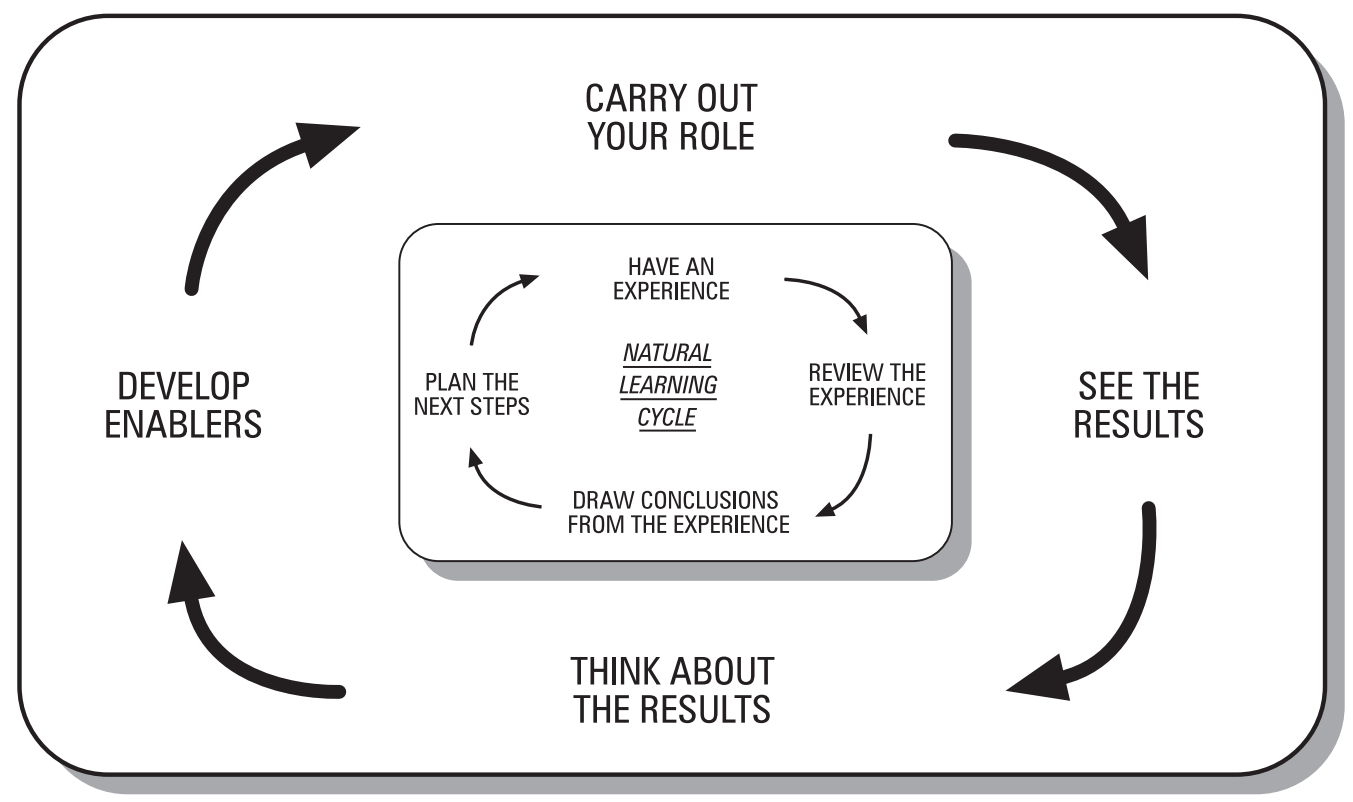

Figure 2 Collaborative learning

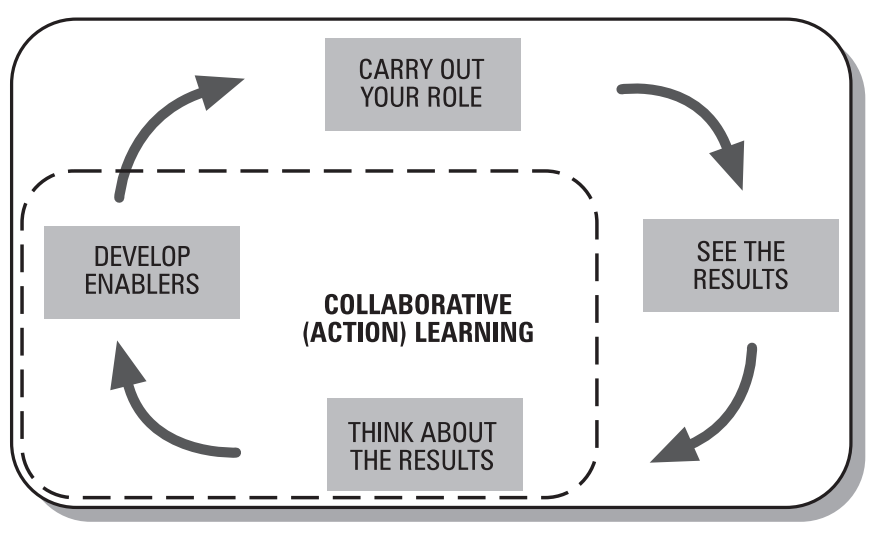

with one another, the more the three circles overlap and the more optimal is performance. The three circles are constantly in dynamic movement; the learning strategy described above is the means by which the circles are moved to try to keep them in harmony. This system has been described in detail elsewhere (Drew and Smith, 1995; Smith, 1993), and was first used successfully in Exxon in the mid-1980s.

In the following section a practical example of the use of these two concepts, and other interventions, in the development of an LO is described.

Figure 3 The performance system

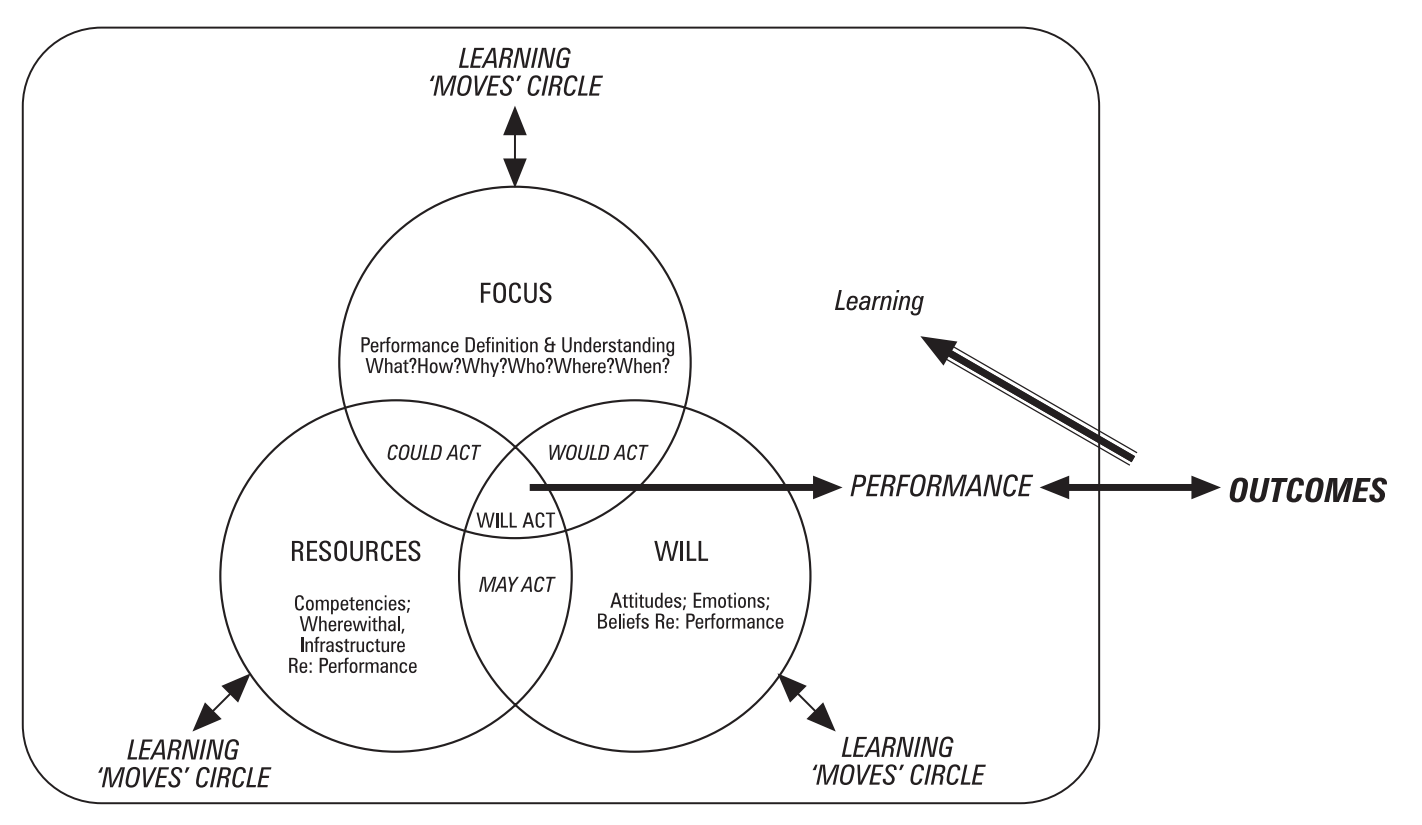




\section{Case study: building a learning organization}

This case study concerns an unlikely candidate for LO development: the Canadian Imperial Bank of Commerce (CIBC). In 1990 when my work began with CIBC, it was a large (over 30,000 employees), traditional, highly successful, diversified bank with hierarchical structures, controls and a rules-driven culture. This case study demonstrates that this organization, despite its size and history, has successfully reinvented its future by pursuing an LO heading, and has learned to operate in new and even more successful ways.

CIBC had always been "the bank that service built", but the new vision it articulated in the early 1990s of becoming a customerobsessed company, driven by the customer, close to the customer, and with everstrengthening relationships with the customers, went far beyond tradition.

A concept which captured the spirit of CIBC's vision was "individuals going the extra mile". CIBC believed that when such discretionary effort became so ingrained that it was commonplace, CIBC would truly be a customer-obsessed company. To assist in realizing this vision the bank adopted a new approach to its business based on the wellknown "inverted pyramid". This in turn demanded new mechanisms for operationalizing the strategy.

I have commented earlier in this paper on the need for management to exercise leadership. First, management must create a meaningful vision and strategy so that employees can see that they are making a contribution. Second, management must emphasize that the business environment is manageable, and that control in the face of complex change is possible. CIBC's management addressed these various concerns through their in-house communications, including face-to-face executive-employee "bear pits". In addition, the bank's executives underlined their dedication and support for this effort through special "strategic direction" issues of their in-house journal.

The LO concept appeared to offer the most promise as a blueprint for the kind of organizational journey CIBC was determined to undertake. However, from the beginning it was realized that strong emphasis initially on learning would be counterproductive in an organization struggling to redesign its rule-based environment, and where highest priority was being placed on becoming "customer obsessed". Rather the culture needed to become one that was "... about people learning to adapt and change as a result of intense competition" (Flood, 1993a, my italics). In addressing the Canadian Payments Association, Al Flood (CIBC's chairman) said "The point here is not to have the organization force employees to learn, but to create a context in which they will want to learn" (Flood, 1993b).

CIBC's approach conforms with Revan's conditions for successful development of an autonomous learning system (Revans, 1982), where the organization's most precious asset is “... its capability to build upon its lived experience, to learn from its challenges and to turn in a better performance by inviting all and sundry to work out for themselves what that performance ought to be". Hubert SaintOnge, the vice-president responsible during this period for CIBC's leadership development, commenting on CIBC's early LO work, said, "We never discuss 'Learning Organizations' at the bank, but talk about enhancing organizational capability" (Saint-Onge, 1993a). In this spirit, the simple learning strategy shown in Figure 1 and the systemic three-element performance model reproduced in Figure 3 were introduced. The way in which the model's three elements of performance (focus, will and capability) drove CIBC's learning efforts has been detailed on a number of occasions (Saint-Onge, 1993a; 1993b).

The simplicity and power of the learning strategy and the performance model ensured that they would become familiar across the bank, and would be rapidly adopted at all levels. It paved the way for the introduction of an LO approach by emphasizing the fundamentals of excellent performance in pursuit of business outcomes, e.g. activities and tools related to customer service. Although it identified the necessary concurrent learning it also helped de-emphasize it by making it more transparent at a practical level; that is learning content and processes were designed, but learning was "by doing". Fritz (1989) states that "Structure determines behaviour". In developing an LO the designers must ponder this statement, and ask themselves "What structure should I adopt to create the results I want to create?".

In support of the "inverted pyramid" strategy people management was early identified as one of the bank's key business drivers $(C I B C$ 
The News, 1992a). The goal was to give employees the support, direction and skills needed to provide customers with the best possible service. This involved changing the traditional roles of employees, managers and the HR function to reflect the new approach Employees were asked to take responsibility for their performance, the service they delivered and the development of their own skills and careers. Managers would be less controlling and would focus on helping employees in their new role, and on removing barriers. HR would evolve from hands-on management to developing and delivering the necessary tools.

The critical impact that management mindsets would have on the successful introduction of CIBC's new strategy including people management, and the development of an LO, was realized from the beginning. It was also understood that having highly skilled managers in periods when new beliefs and strategies were being introduced could not be overvalued (Donaldson and Lorsch, 1983).

Structuring learning for CIBC's LO was based on four key premises:

(1) The approach must be systemic.

(2) The influence of management was so critical that their needs must be addressed first.

(3) Behaviours and habits must be changed to change thinking and learning, not the other way round.

(4) The effort must be focused on performance and it must be business "outcomes" driven

A major consideration for CIBC was where to make a start. The first step was to examine the contribution of traditional training to the bank's capabilities. It quickly became apparent that CIBC had been dedicating significant resources to formal training, and that it was one of the leaders in the banking industry in this regard. Unfortunately it was equally clear that this effort had been ill-focused and had become largely ineffective. It also became clear that any attempt to design a more efficient training strategy would be outdated with respect to CIBC's emerging needs, although training itself would continue to have a key role to play.

One of the first major structural changes involved replacing the training-oriented Staff College with a central Leadership Centre (CIBC The News, 1992b) and a distributed national network of Employee Development Centres (CIBC The News, 1992b). The Leadership Centre's goal was to enhance the leadership qualities of the bank's managers; a key requirement for a successful LO. The Centre offers programs and workshops designed to reinforce CIBC's business strategies and contribute to their renewal through management involvement. The development centres help employees across Canada develop new skills for wining customer loyalty in current and future jobs. These centres utilize self-directed learning products as well as workshops, self-assessment tools and individual consultations in support of career planning and development.

Concurrently with setting up the above centres, extensive competency modeling was undertaken to identify business outcomes and link them with new roles and competencies to achieve them. These models were then applied to career streams and resourcing across 3,500 jobs within the bank. For example, outcomes were defined to ensure that desirable business- and people-management-related behaviours would be demonstrated. Based on the three-element performance framework described above, a new "role of the manager" was defined. This role identified those behavioural requirements for managers which were deemed necessary to deliver the desired business outcomes. When consensus for the new role of the manager had been reached, the performance framework provided the means to identify the required core competencies, and flesh out relevant enablers for the learning strategy. A learning curriculum was then designed by the Leadership Centre to develop the managerial and leadership behaviours described in the role of the manager.

However, in the spirit of the LO, Hubert Saint-Onge, the vice-president responsible for the Leadership Centre has said, “The bank's Leadership Centre is not about competencies and skills. It's about mindsets. The Centre becomes a place of sharing; a forum for the exchange of information. A place where assumptions are constantly probed and pushed and tested; new ways designed; new strategies formulated" (Saint-Onge, 1993a). Saint-Onge also said "The role of CIBC's Leadership Centre is to provide the organization with systematic practices for the generation and renewal of our capabilities as an organization" (Saint-Onge, 1996). CIBC passed more than 3,000 managers through its foundation program that is based on changing mindsets from "If I give them (my employees) half a chance they'll do something wrong" to 
"If I give them half a chance they'll do something right" (Saint-Onge, 1996). The result "... demonstrates how huge strides can be made in bottom-line results when the assumptions that shape the business are aligned with the new realities of the business environment" (Saint-Onge, 1996).

CIBC successfully traveled from its traditional hierarchical environment to the "inverted pyramid" in only $3 \frac{1}{2}$ years and has maintained its momentum through the decade. This has been possible because the basic environment was properly designed and created. CIBC adopted a "middle up-down" approach; first targeting a middle-management segment in a strategically important non-mainstream part of the company. These managers then influenced their supervisors and their subordinates. Once the LO effort had matured, the accent was more specifically placed on learning. For example, Al Flood eventually talked openly about CIBC as an LO (Flood, 1993c); learn-to-learn skills (Honey and Mumford, 1989) and traditional action learning (Pedler, 1991) were introduced into the curriculum.

There are many lessons to be drawn from CIBC's efforts over the last ten years as the bank launched and pursued its LO journey. Perhaps of the greatest importance is that if an organization of this size and tradition can successfully implement LO principles then others can certainly do the same. This case also indicates that an LO approach provides an enterprise with fundamental capabilities which are the keys to business success not only now but into the new millennium.

\section{References}

Ackoff, R.L. (1981), Creating the Corporate Future, John Wiley \& Sons, New York, NY.

Argyris, C. (1993), Knowledge for Action, Jossey-Bass, San Francisco, CA.

Argyris, C. and Schon, D.A. (1978), Organizational Learning: A Theory of Action Perspective, AddisonWesley, Reading, MA.

CIBC the News (1992a), "CIBC - the way forward", Vol. 25 No. 6

CIBC the News (1992b), "Employee development centres: building CIBC's competitive edge through people", Vol. 25 No. 7.

Donaldson, G. and Lorsch, J.W. (1983), Decision Making at the Top, Basic Books, New York, NY.

Drew, S.A.W. and Smith, P.A.C.(1995), "The learning organization: 'change proofing' and strategy", The Learning Organization, Vol. 5 No. 1.
Drucker, P.F. (1992), Managing for the Future, Truman Talley Books.

Drucker, P.F. (1993), Post Capitalist Society, Butterworth Heinemann, Oxford.

Flood, A.L. (1993a), "CIBC the News", Leadership through Learning, Vol. 26 No. 2.

Flood, A.L. (1993b), "The business of business is learning", address to the Canadian Payments Association, Vancouver, Canada, 26 April.

Flood, A.L. (1993c), "The learning organization", 62nd Annual Coaching Conference on the Challenge of Lifelong Learning in an Era of Global Change, Geneva Park, 7 August.

Fritz, R. (1989), The Path of Least Resistance, Fawcett Columbine.

Garvin, D.A. (1993), "Building a learning organization", Harvard Business Review, July-August

Hampden-Turner, C. (1992), Creating Corporate Culture, Addison-Wesley, Reading, MA.

Handy, C. (1990), The Age of Unreason, Harvard Business School Press, Boston, MA.

Honey, P. and Mumford, A. (1989), The Manual of Learning Opportunities.

Kofman, F. and Senge, P.M. (1993), "Communities of commitment: the heart of learning organizations", pre-publication draft, System Dynamics.

Morris, L.E. (1995), "Development strategies for the knowledge era", in Chawla, S. and Renesch, J. (Eds), Learning Organizations, Productivity Press.

Nonaka, I. and Takeuchi, H. (1995), The Knowledge Creating Company, Oxford University Press, Oxford.

Pedler, M. (Ed.) (1991), Action Learning in Practice, 2nd ed., Gower, Aldershot.

Pedler, M., Burgoyne, J. and Boydell, T. (1989), "The learning company", Studies in Continuing Education, Vol. 11 No. 2.

Revans, R.W. (1982), "The enterprise as a learning system", The Origins and Growth of Action Learning, Chartwell-Bratt, Bromley.

Saint-Onge, H. (1993a), "Towards implementation, valuing the learning organization", Ernst \& Young Professional Development Symposium Journal.

Saint-Onge, H. (1993b), "Enhancing organizational capability: applying principles of the learning organization", The Canadian Institute Conference on The Learning Organization, Toronto, Canada, 21 and 22 June.

Saint-Onge, H. (1996), "Tacit knowledge: the key to the strategic alignment of intellectual capital", Strategy \& Leadership, January.

Senge, P.M. (1990), The Fifth Discipline, Doubleday, New York, NY.

Schein, E.H. (1992), Organizational Culture and Leadership, 2nd ed., Jossey-Bass,San Francisco, CA.

Smith, P.A.C. (1993), "Getting started as a learning organization", in Watkins, K.E. and Marsick, V.J., Sculpting the Learning Organization, Jossey-Bass, San Francisco, CA.

Smith, P.A.C. and Saint-Onge, H. (1996), "The evolutionary organization: avoiding a titanic fate", The Learning Organization, Vol. 3 No. 4.

Smith, P.A.C. and Tosey, P. (1999), "Assessing the learning organization - part 1: theoretical foundations", The Learning Organization, Vol. 6 No. 1. 